\title{
Optimal Hedge Ratios Under the Presence of a Forward Curve Bias
}

\author{
Camilo Sarmiento* \\ Inter-American Development Bank, Washington, DC, USA
}

*Corresponding Author: Camilo Sarmiento, Inter-American Development Bank, Washington, DC, USA

\begin{abstract}
We derive optimal hedging ratios for interest rate risk under different assumptions that underpin the relationship between the forward rate and the expected future spot rate. In some instances, full hedging is optimal, and the conditions for the optimality of a partial hedge are identified. Less hedging (more floating debt in our model) is more optimal under the liquidity preference model than under the unbiased expectations hypothesis. This indicates that in times of higher preference for liquidity less hedging is optimal. Higher preference for liquidity correlates with larger term spreads (a steeper yield curve) and periods of monetary easing. Comparison of the analytical results with historical data indicates that partial hedging for interest rate risk is generally preferable over full hedging strategies with some exceptions. Lastly, the paper shows the role of market timing on hedging decisions.
\end{abstract}

Keywords: Hedge Ratios, Forward Rate, Expected Spot Rate, Profit Maximization, Expected Utility.

\section{INTRODUCTION}

In the financial services industry, the forward curve is a common metric used for forecasting the short-term rate. Samuelson's (1965) original formulation of efficient markets presumes that the forward rate is the best forecast of the spot rate. Samuelson interprets the future price as concrete observations of the spot price anticipations, and states that examinations of past changes in the forward curve does not improve forecast ability. ${ }^{1}$ The unbiased expectations hypothesis (see Gibson et al., 2010) states that the forward rate is equal to the future expected spot rate. Hicks' liquidity preference model, instead, projects that the forward market is in constant contango (i.e., forward rate exceeds the expected spot rate). Lastly, the preferred habitat theory is consistent with a future market that is in either contango or normal backwardation.

In this paper, we examine optimal firm behavior under the unbiased expectations hypothesis and the effect of violations of this hypothesis on hedging behavior for interest rate risk. The analytical results underscore scenarios for which full hedging is preferable over partial hedging strategies and viceversa. Less hedging (more floating debt in our model) is more optimal under the liquidity preference model than under the unbiased expectations hypothesis. This indicates that in times of higher preference for liquidity less hedging is optimal. Higher preference for liquidity correlates with larger term spreads (a steeper yield curve) and periods of monetary easing.

A corollary of our analytical model is that the level of floating debt (less hedging in our model) positively correlates with the difference between forward rate and the expected spot rate. This result in consistent with Chernenko and Faulkender (2011) empirical finding that firms prefer more floating debt when the term structure is steep.

Furthermore, comparison of the analytical results with historical data indicates that full hedging (in the Libor market) is optimal only under very specific economic conditions, while a partial hedge is more optimal in most economic environments.

The derived analytical results also underscore that risk aversion is not a necessary condition for hedging, and profit-making motivations are intertwined with hedging strategies. A profit maximizing

${ }^{1}$ Limitations of the forward curve for spot rate forecasting have been well established in the literature (Shiller et al., 1983; Fama, 1984; Fama and Bliss, 1987; Campbell and Shiller, 1991; Piazzesi and Swanson, 2004). 
institution will use interest rate derivatives for speculative activities only in specific economic environments. This finding partly conciliates some diverging views on the use of interest rate derivatives for other purposes than hedging. For example, Faulkender (2005) and Chernenko and Faulkender (2011) indicate that firms use interest rate derivatives for both hedging and speculative activities, while Allen et al. (2012) analysis indicates that hedging is the dominant factor.

Lastly, we show the role of market timing on hedging decisions.

\section{ASSUMPTIONS}

The paper follows a set of assumptions that intend to make the analysis more tractable. These assumptions are:

1. The bank lending rate is fixed, while the borrowing rate is floating. ${ }^{2}$

2. For simplicity and without loss of generality, interest rate uncertainties are modelled in a static framework.

3. The objective function of the bank is to maximize expected utility, i.e., maximize profit with a risk premium component.

4. The utility function exhibits constant absolute risk aversion in order to increase tractability of the analytical derivations.

\section{BASIC BANK OPTIMIZATION PROBLEM}

Mathematically, the objective function of a private bank is:

(1) $\operatorname{Max}_{Y, K} \pi(Y, K)=R \times Y-B R\left(\frac{Y}{K}\right) \times[Y-K]$

where

$\mathrm{R}=$ Lending rate;

$\mathrm{Y}=$ Outstanding balance;

$\mathrm{BR}=$ Borrowing rate defined as a continuously differentiable function that is convex with respect to the asset to equity ratio, $\mathrm{Y} / \mathrm{K}$; and

$\mathrm{K}=$ Bank's Equity (Capital).

However, we assume that in the short-term equity is constrained and, therefore, the objective function reduces to:

(2) $\operatorname{Max}_{Y} \pi(Y)=R \times Y-B R\left(\frac{Y}{K}\right) \times[Y-K]$.

The optimal choice for lending volume thus satisfies the first order condition:

(3) $R-B R-\frac{\partial B R}{\frac{\partial Y}{K}} \times\left[\frac{1}{K}\right] \times[Y-K]=0$.

From Equation 3, lending fees and equity levels explain lending levels. In particular, at the optimal choice, a profit maximizing bank selects outstanding loan balances so that the total cost of an additional unit of lending equals the lending rate. Alternatively stated, the optimal asset-to-equity ratio is the point in which firm value is maximized. That is, the point where marginal cost of debt just offsets marginal benefits.

The solution of the optimization hinges on the condition that:

$\partial^{2} B R / \partial(Y / K)^{2}>0$.

Note that the second order condition is the market intrinsic constraint on growth. That is, optimal growth rates based on leverage are constrained by the equity-to-asset ratio. This assumption is

\footnotetext{
${ }^{2}$ This paper focuses on optimal hedging of floating rate debt. Of course, there are other motivations for hedging not modelled in this paper, e.g., use of hedging to avoid costly external financing by better matching internal cash flow with financing needs (see Froot, Scharfstein, and Stein, 1993).
} 
intuitive, as the borrowing rate does increase at an increasing rate (in absolute terms) across rating grades.

\section{OPTIMAL INTEREST RATE HEDGING: UNBIASED EXPECTATION HYPOTHESIS}

To calculate optimal hedging ratios, we assume that the borrowing rate is:

$$
B R=B R\left(\frac{Y}{K}\right)+L R
$$

where

$L R \sim N\left(\overline{L R}, \sigma^{2}\right)$.

Note that $L R$ can be interpreted as the Libor rate that fluctuates with market conditions and, therefore, has a random component.

Under the unbiased expectations hypothesis, the forward rate equals the expected spot rate and, therefore,

$$
E(L R)=\overline{L R}=F R
$$

where $F R$ is the forward rate.

Hedging occurs under the unbiased expectations hypothesis only if the bank is risk averse. Specifically, under risk aversion and an uncertain interest rate scenario, the optimization in (2) is generalized as follows:

(4) $\left.\operatorname{Max}_{Y} \pi(Y, K)=U\left\{R \times Y-B R\left(\frac{Y}{K}\right) \times[Y-K]-\overline{(L R}+R P\right) \times[Y-K]\right\}$

where

$$
\text { Risk premium }=R P=R P\left(\sigma^{2}, \pi, U\right), \quad \text { for } \partial R P / \partial \sigma^{2}>0 .
$$

Furthermore, under the assumption of constant absolute risk aversion,

$\frac{\partial R P}{\partial \pi}=0$.

To introduce the optimal hedging ratio, we assume that the bank can lock some of the funding cost with the forward curve, FR, as follows:

(5) $\left.\operatorname{Max}_{Y, \tau} \pi(Y, K, \tau)=U\left\{R \times Y-B R\left(\frac{Y}{K}\right) \times[Y-K]-\tau \times \overline{(L R}+R P\right) \times[Y-K]\right\}-(1-\tau) \times F R$

$$
\times[Y-K]\}
$$

where $(1-\tau)$ is the hedge ratio and $\tau \in[0,1]$.

The first order conditions of the optimization in (5) are:

$$
\begin{gathered}
\text { (6a) } \left.\frac{\partial U}{\partial \pi} \times\{R-B R-\tau \times \overline{(L R}+R P)-(1-\tau) \times F R-\frac{\partial B R}{\frac{\partial Y}{K}} \times\left(\frac{1}{K}\right) \times[Y-K]\right\}=0 . \\
\left.(6 \mathrm{~b})-\frac{\partial U}{\partial \pi} \times\left\{[\overline{(L R}+R P)-F R+\tau \frac{\partial R P}{\partial \tau}\right] \times[Y-K]\right\} \leq 0 .
\end{gathered}
$$

where $\frac{\partial F R}{\partial \tau}>0$.

Under the unbiased expectation hypothesis, the optimization reduces to:

(7a) $\frac{\partial U}{\partial \pi} \times\left\{R-B R-\tau \times R P-F R-\frac{\partial B R}{\frac{\partial Y}{K}} \times\left(\frac{1}{K}\right) \times[Y-K]\right\}=0$.

$(7 b)-\frac{\partial U}{\partial \pi} \times\left\{\left[R P+\tau \frac{\partial R P}{\partial \tau}\right] \times[Y-K]\right\} \leq 0$.

However, Equation $7 \mathrm{~b}$ is necessarily negative since 


$$
R P+\tau \frac{\partial R P}{\partial \tau}>0
$$

Therefore, the optimal allocation of borrowing is to fully hedge, $\tau=0$, for interest rate risk as long as the bank is risk averse.

Now, if the bank fully hedges interest risk, then the bank can effectively lend more than the case the bank does not use the forward market, as

$$
F R<\overline{L R}+R P
$$

in (5) results in a higher level of lending under full hedging.

The results derived under a private bank also apply for a public bank, represented by the objective function (see Sarmiento, 2018):

(8) $\left.\operatorname{Max}_{Y, \tau} \pi(Y, K, \tau)=U\left\{R \times Y-B R\left(\frac{Y}{K}\right) \times[Y-K]-\tau \times \overline{(L R}+R P\right) \times[Y-K]\right\}-(1-\tau) \times F R$ $\times[Y-K]\}+T(Y, L R)$

where

$T(Y, L R)=$ Social benefit from both lending and the fees related to the lending.

Note that under the optimization function in (8) and the unbiased expectations hypothesis, the first order condition in (7b) does not change and, therefore, the optimal hedging ratio under the assumption of a private bank's objective function extends to the case of a public bank's objective function.

\section{Optimal Interest Rate Hedging: Under Departures From The Expectations HYPOTHESIS}

The optimal use of hedging is straightforward under the assumption that markets are efficient. However, the optimal hedge ratio is confronted, more realistically, under the condition:

$$
E(L R)=\overline{L R} \neq F R .
$$

That is, the forward Libor rate is not generally an unbiased predictor of the spot rate. In this instance, full hedging may not be optimal. Moreover, hedging becomes an instrument used by both risk neutral agents and speculators. The process of hedging and profit making then becomes intertwined.

To evaluate the optimization in (5) under alternative hypotheses, we first assume that

(9) $\overline{L R}>F R$.

This case generates the same results than the unbiased expectation hypothesis. That is, full hedging is optimal, and it contributes to more lending.

However, full hedging is not necessarily optimal if

(10) $\overline{L R}<F R$.

This case corresponds to Hicks' liquidity model.

Specifically, under (10), the first order conditions of the optimization in (5) are:

$$
\text { (11a) } \left.\frac{\partial U}{\partial \pi} \times\{R-B R-\tau \times \overline{(L R}+R P)-(1-\tau) \times F R-\frac{\partial B R}{\frac{\partial Y}{K}} \times\left(\frac{1}{K}\right) \times[Y-K]\right\}=0 \text {. }
$$

(11b) $\left.-\frac{\partial U}{\partial \pi} \times\left\{[\overline{(L R}+R P)-F R+\tau \frac{\partial R P}{\partial \tau}\right] \times[Y-K]\right\} \leq 0$ or $>0$.

Equation (11b) is no longer necessarily negative under (10), and a full hedging strategy is no longer optimal in many cases. For example, from (11b), no hedging is optimal if:

$$
\text { (12) } \left.\quad F R>\overline{(L R}+R P+\tau \frac{\partial R P}{\partial \tau}\right) \text {, for all } \tau \text {. }
$$

That is, if (12) holds, then (11b) is positive and, therefore, $\tau=1$. 
An interior solution to the optimization problem in (11) corresponds to the solution in which partial hedging is optimal. That is,

$$
\left.-\frac{\partial U}{\partial \pi} \times\left\{[\overline{(L R}+R P)-F R+\tau \frac{\partial R P}{\partial \tau}\right] \times[Y-K]\right\}=0 .
$$

A necessary condition for the optimality of partial hedging is, therefore,

$$
F R>\overline{(L R}+R P) \text {. }
$$

The sensitivity of the risk premium with respect to the hedge ratio thus determines the optimal ratio under a partial hedging solution. In addition, a higher risk premium (higher $\sigma$ ) implies that lower lending (lower $Y / K$ ) needs to be maintained, and a higher hedge ratio is optimal.

\section{Comparison of the Analytical ReSults with Historical Data}

The previous section established that partial hedging is optimal over full hedging if

$$
F R>\overline{(L R}+R P) \text {. }
$$

However, the likelihood of such event cannot be established analytically, and the use of actual data is necessary. Figures 1 to 7 show the historical relation between the forward curve and the realized spot price in the last 20 years. The historical data points to the premise that the Libor forward market tends to be in contango,

$$
F R>\overline{L R},
$$

in most economic environments. For example, Figure 2 indicates that the forward rate exceeded the realized spot rate by a wide margin during the financial crisis. The implied high liquidity premium during that period provided incentives to have a larger proportion of floating debt or less hedging in the context of our model. Some historical exceptions are apparent. For example, the forward Libor rate appears to have been in backwardation in 2016 - as the Federal Reserve started the tightening cycle in Figure 6.

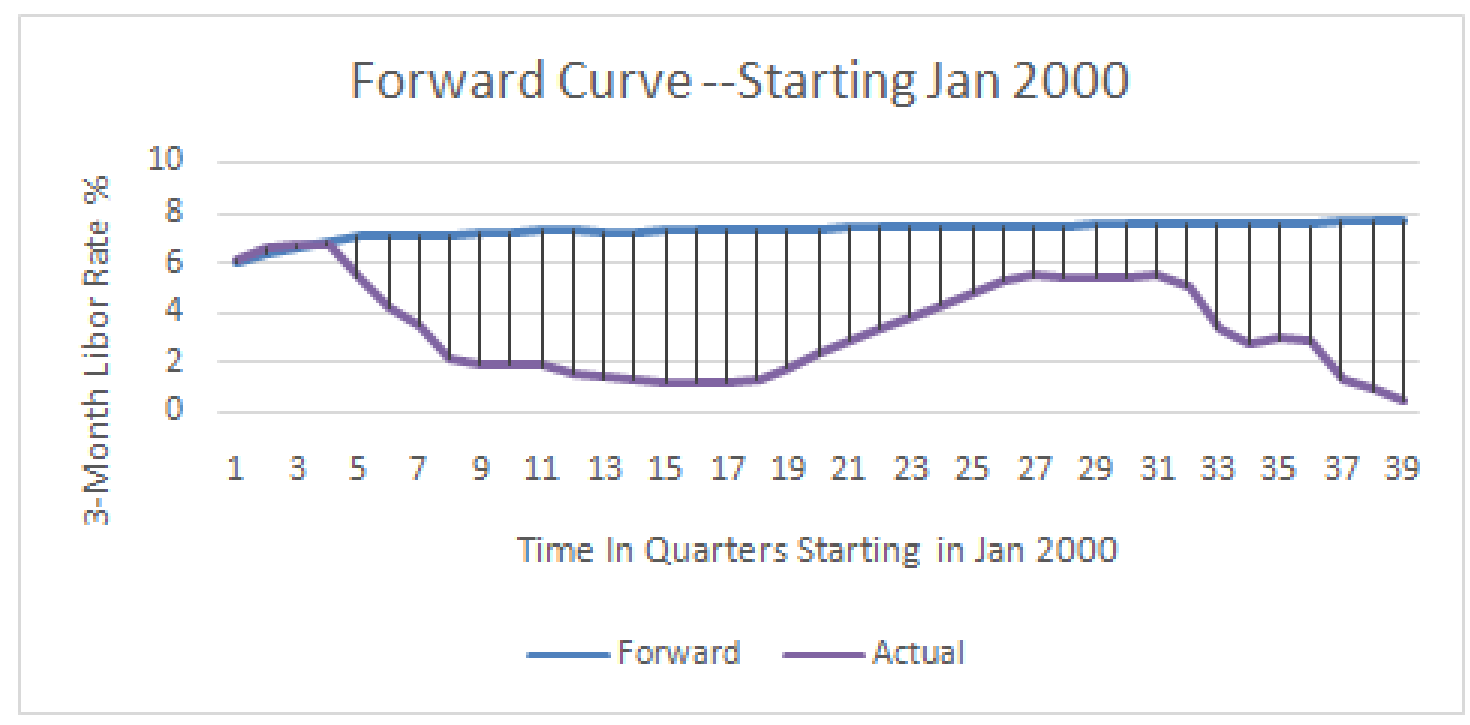

Figure1. Model Fit Forward Curve in 2000 


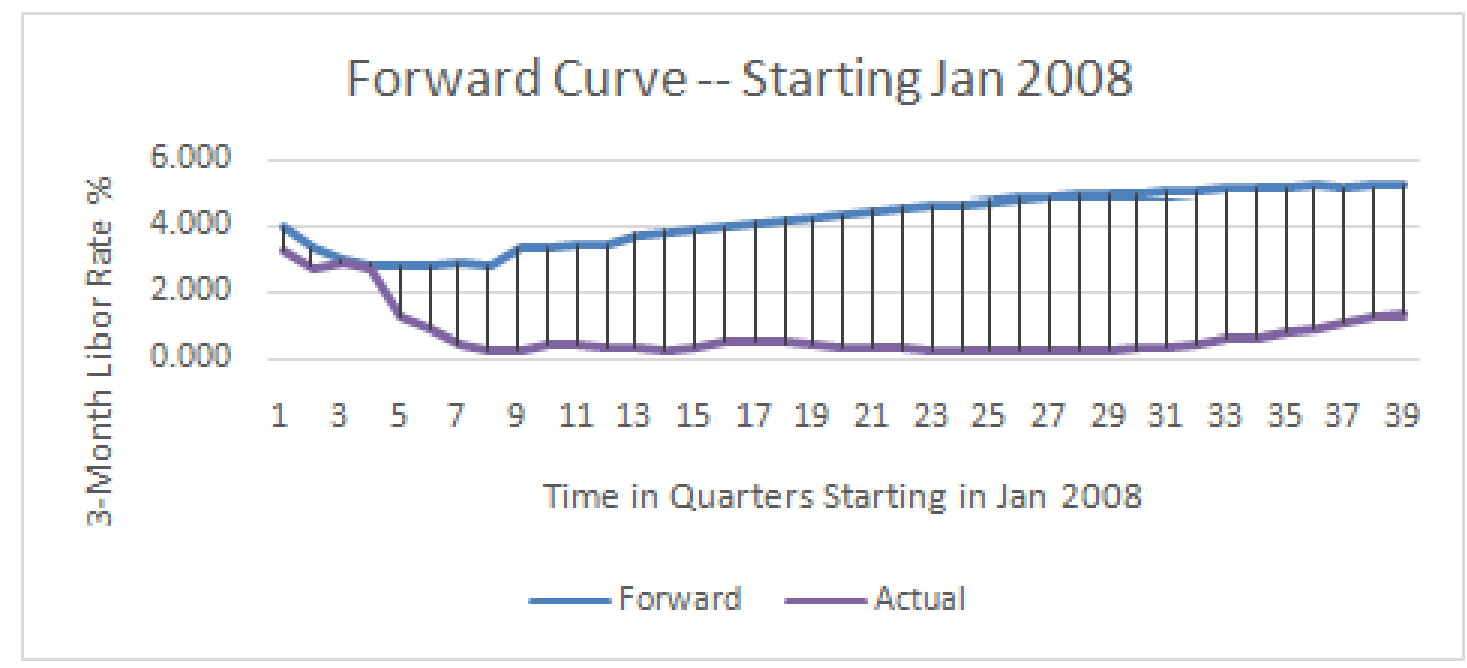

Figure2. Model Fit Forward Curve in 2008

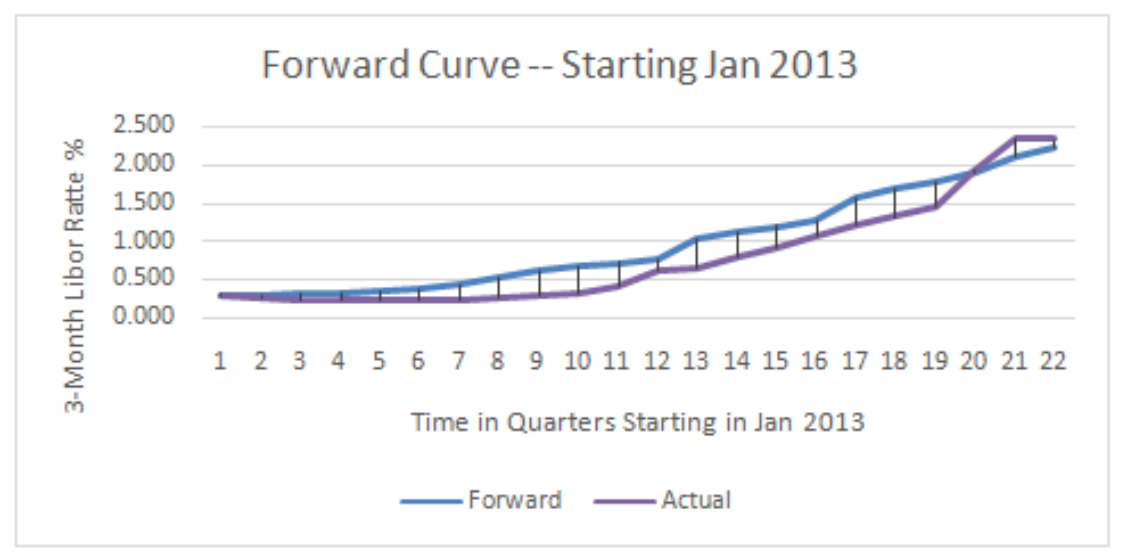

Figure3. Model Fit Forward Curve in 2013

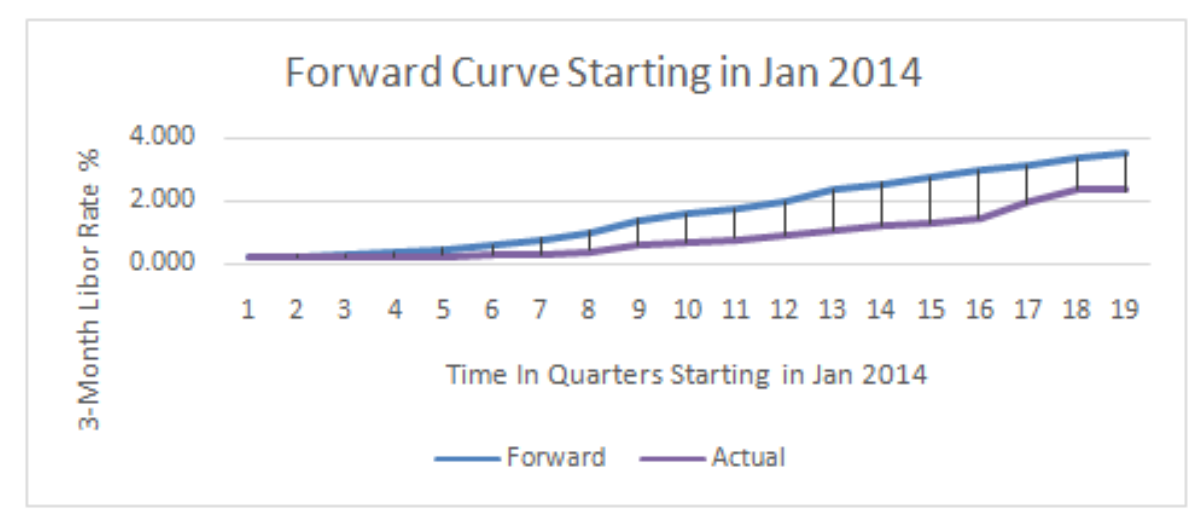

Figure4. Model Fit Forward Curve in 2014 


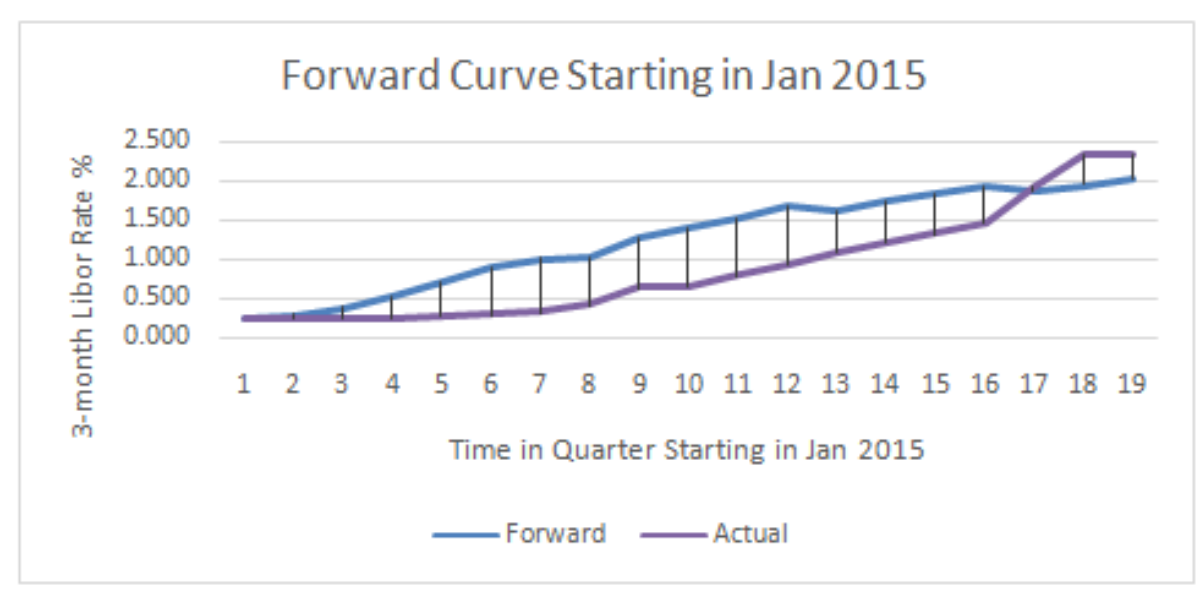

Figure5. Model Fit Forward Curve in 2015

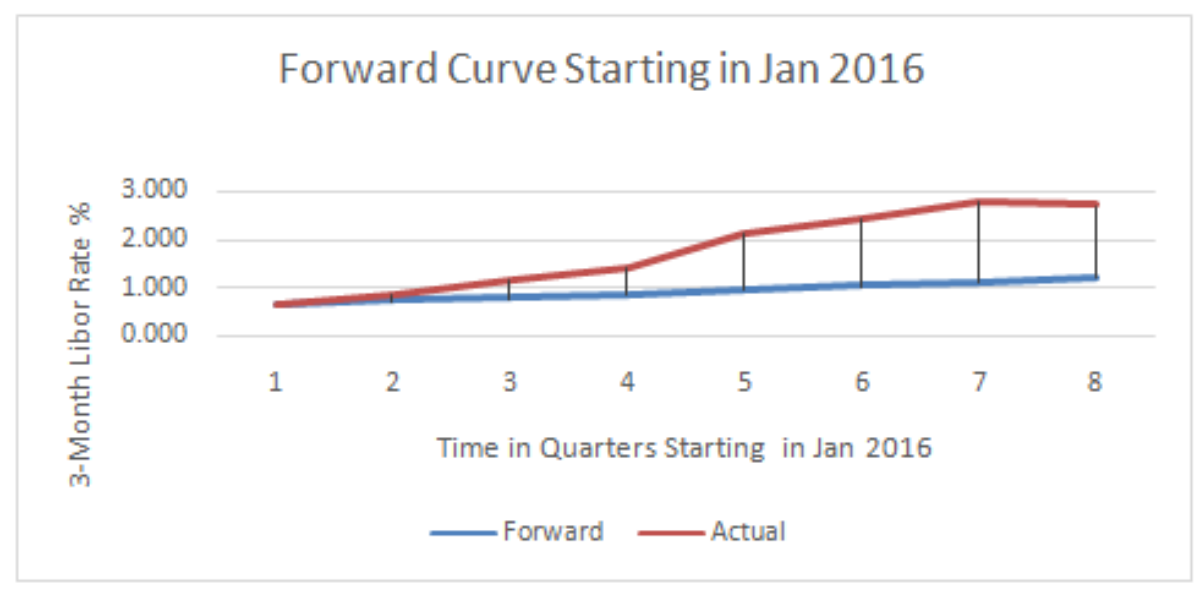

Figure6. Model Fit Forward Curve in 2016

\section{Optimal Interest Rate Hedging: Under Time VARYing ForWard Prices}

The optimal hedge ratio derivations become more complicated when the timing to lock a forward position is also a control variable at the bank. To that end, we allow timing of the hedge is a control variable in addition to the hedge ratio. To extend such choice in (5), we assume (for simplicity sake) that within the static framework that there are two forward contracts. One fully eliminates interest rate uncertainty and the second contract embeds a lower maturity date that does not fully hedge the position.

The objective function in (5) is then extended as follows:

$$
\begin{gathered}
\text { (13) } \left.\operatorname{Max}_{Y, \tau} \pi(Y, K, \tau)=U\left\{R \times Y-B R\left(\frac{Y}{K}\right) \times[Y-K]-\tau_{1} \times \overline{(L R}+R P\right) \times[Y-K]\right\}-\tau_{2} \times F R_{2} \\
\left.\left.\left.+R P_{2}\right) \times[Y-K]\right\}-\left(1-\tau_{1}-\tau_{2}\right) \times F R \times[Y-K]\right\}
\end{gathered}
$$

where $\left(1-\tau_{\mathrm{i}}\right)$ is the hedge ratio under contract $\mathrm{i}$ and $\tau_{\mathrm{i}} \in[0,1] ; F R_{2}$ is the forward price that does not fully cover the redemption period of the debt maturity and, therefore, embeds a residual risk premium, $F R_{2}$.

The first order conditions of the optimization in Equation 13 are:

$$
\begin{gathered}
(14 a) \frac{\partial U}{\partial \pi} \times\left\{R-B R-\tau_{1} \times \overline{(L R}+R P\right)-\tau_{2} \times\left(F R_{2}+R P_{2}\right)-\left(1-\tau_{1}-\tau_{2}\right) \times F R \\
\left.-\quad \frac{\partial B R}{\frac{\partial Y}{K}} \times\left(\frac{1}{K}\right) \times[Y-K]\right\}=0 .
\end{gathered}
$$

$\left.(14 b)-\frac{\partial U}{\partial \pi} \times\left\{[\overline{(L R}+R P)-F R+\tau_{1} \frac{\partial R P}{\partial \tau_{1}}\right] \times[Y-K]\right\} \geq$ or $<0$. 


$$
(14 c)-\frac{\partial U}{\partial \pi} \times\left\{\left[\left(F R_{2}+R P_{2}\right)-F R+\tau_{2} \frac{R P_{2}}{\partial \tau_{2}}\right] \times[Y-K]\right\} \geq \text { or }>0 .
$$

Under the unbiased expectations hypothesis,

$$
E\left(L R_{t}\right)=F R
$$

and

$$
E\left(L R_{t-s}\right)=F R_{2}
$$

where the subscript $t$ - sis used to refer to the forward price that does not fully cover the redemption period of the debt maturity.

Now, if

$$
F R<F R_{2}+R P_{2}
$$

then the strategy to fully hedge interest rate risk is still optimal as both (14b) and (14c) are negative. However, if the forward market provides the opportunity for lower rates at lower maturities,

$F R>F R_{2}+R P_{2}$,

then the Bank may pursue partial hedging even under the unbiased expectation hypothesis. Lastly, under Hicks' liquidity preference model, the likelihood of market timing in hedging decision increases.

\section{CONCLUSION}

From the analytical derivations, the decision to hedge is straightforward. In some cases, full hedging is optimal, and the conditions for the optimality of a partial hedge are identified. Less hedging is more optimal under the liquidity preference model than under the unbiased expectations hypothesis. This indicates that in times of higher preference for liquidity less hedging is optimal. Higher preference for liquidity correlates with larger term spreads and periods of monetary easing.

Comparison of the analytical results with historical data, however, indicates that full hedging (in the Libor market) is optimal only under very specific economic conditions, while a partial hedge is more optimal in most economic environments.

During the financial crisis, the forward Libor rate exceeded the realized spot rate by a wide margin. The implied high liquidity premium during that period provided incentives to have a larger proportion of floating debt or less hedging in the context of our model. In the post Great Recession period, the difference between forward price and the expected price narrowed, which concluded in a period of normal backwardation as the Federal Reserve started the tightening cycle in 2016.

The derived analytical results also underscore that risk aversion is not a necessary condition for hedging, and profit-making motivations are intertwined with hedging strategies. A profit maximizing institution will use interest rate derivatives for speculative activities only in specific economic environments. This finding partly conciliates some diverging views on the use of interest rate derivatives for other purposes than hedging. For example, Faulkender (2005) and Chernenko and Faulkender (2011) indicate that firms use interest rate derivatives for both hedging and speculative activities, while Allen et al. (2012) analysis indicates that hedging is the dominant factor.

\section{REFERENCES}

[1] Allen, A. Kim, S., Zitzler, M. (2012) "Hedging Instrument in Post Liquidity Crisis: A Case of Interest Rate Swaps." Managerial Finance, 39, 47-59,

[2] Campbell, J. Y., and Shiller, R. J. (1991) "Yield Spreads and Interest Rate Movements: A Bird's Eye View." Review of Economic Studies, 58, 495-514.

[3] Chernenko, S., and Faulkender, M. (2011). "The Two Sides of Derivatives Usage: Hedging and Speculating with Interest Rate Swaps."Journal of Financial and Quantitative Analysis, 46, 1727-1754.

[4] Fama, E., (1984) "The Information in the Term Structure," Journal of Financial Economics, 13, 509-28.

[5] Fama, E and BlissR. (1987) "The Information in Long-Maturity Forward Rates", American Economic Review, 77, 680-92. 
[6] Faulkender,M. (2005) "HedgingorMarketTiming?SelectingtheInterestRateExposureofCorporateDebt." Journal of Finance, 60, 931-962.

[7] Froot, K. A., Scharfstein, D. S., and Stein, J. C. (1993) "Risk Management: Coordinating Corporate Investment and Financing Policies." Journal of Finance, 48, 1629-1648.

[8] Gibson, R., Lhabitant, F.-S. And Talay, D. (2010) "Modeling the Term Structure of Interest Rates: A Review of the Literature, Foundations and Trends" in Finance, 5, 1-156.

[9] Piazzesi, M., and Swanson, E. (2004) "Futures Prices as Risk Adjusted Forecasts of Monetary Policy." NBER Working Paper No. 10547.

[10] Samuelson, P. A. (1965)"Rational Theory of Warrant Pricing”. Industrial Management Review 6, 13-39.

[11] Sarmiento, C. (2018) "Optimal Financial Ratios in a Public Bank versus a Private Bank."SSRN Economics Research Network.

[12] Shiller. R., Campbell, J.Y., and Schoenholtz, K.L. (1983) "Forward Rates and Future Policy: Interpreting the Term Structure of Interest Rates," Brookings Papers on Economic Activity, 173-217.

\section{AUTHOR'S BIOGRAPHY}

Camilo Sarmiento, Ph.D., has expertise in the areas of econometrics, finance, risk modeling, and macroeconomic forecasting. Camilo has published more than 35 articles in peer-referred journals as well as produced over 60 internal technical reports on model testing and development for top financial institutions. He has also worked as an Assistant Professor, Associate Research Scientist, and Consultant for universities and non-profit organizations. In his spare time, Camilo created the blog, Insights on Financial News.

Citation: Camilo Sarmiento. "Optimal Hedge Ratios Under the Presence of a Forward Curve Bias" International Journal of Managerial Studies and Research (IJMSR), vol 8, no. 12, 2020, pp. 46-54. doi: https://doi.org/10.20431/2349-0349.0812005.

Copyright: (c) 2020 Authors. This is an open-access article distributed under the terms of the Creative Commons Attribution License, which permits unrestricted use, distribution, and reproduction in any medium, provided the original author and source are credited. 